\title{
Correction to: Mite color alteration and acaricidal activity of 3,7-dimethyl-2,6-octadienal and its structural analogues against the stored food pest mite Tyrophagus putrescentiae
}

\author{
J. E. Song ${ }^{1} \cdot$ H. S. Lee ${ }^{1}$ (D) \\ Published online: 16 May 2019 \\ ๑) Springer Nature Switzerland AG 2019
}

\section{Correction to: Experimental and Applied Acarology (2018) 76:355-363 https://doi.org/10.1007/s10493-018-0318-z}

Due to an unfortunate turn of events, an incorrect funding note was provided in the original publication as it should have read:

Funding This research was supported by Republic of Korea (Government-wide R\&D Fund project for infectious disease research, HG18C0055).

Publisher's Note Springer Nature remains neutral with regard to jurisdictional claims in published maps and institutional affiliations.

The original article can be found online at https://doi.org/10.1007/s10493-018-0318-z.

H. S. Lee

hoiseon@jbnu.ac.kr

J. E. Song

sje626@jbnu.ac.kr

1 Department of Bioenvironmental Chemistry, Chonbuk National University, Jeonju 54896, Republic of Korea 